\title{
Insulin resistance is a major determinant of myocardial blood flow impairment in anginal patients
}

\author{
Riccardo Liga • Daniele Rovai • Tiziana Sampietro • \\ Cecilia Vecoli • Giancarlo Todiere • Chiara Caselli • \\ Giuseppe Rossi • Antonio L'Abbate • Danilo Neglia
}

Received: 20 April 2013 / Accepted: 17 July 2013 /Published online: 11 September 2013

(C) Springer-Verlag Berlin Heidelberg 2013

\begin{abstract}
Purpose In patients with chest pain, stress-induced myocardial perfusion abnormalities are often the result of depressed myocardial blood flow (MBF) reserve. We investigated the relative contribution of cardiovascular risk factors and coronary atherosclerosis to MBF abnormalities in anginal patients.

Methods We studied 167 patients with typical $(n=100)$ or atypical $(n=67)$ chest pain who underwent quantitative evaluation of MBF by PET at rest and after dipyridamole infusion, and quantitative coronary angiography (invasive or by 64slice CT). Patients with left ventricular (LV) dysfunction (ejection fraction $<45 \%$ ) were excluded. Coronary atherosclerosis of $\geq 50 \%$ was defined as obstructive.

Results At rest median MBF was $0.60 \mathrm{ml} \mathrm{min}^{-1} \mathrm{~g}^{-1}$, and after dipyridamole infusion median MBF was $1.22 \mathrm{ml} \mathrm{min}^{-1} \mathrm{~g}^{-1}$. MBF reserve was $<2$ in 77 of 167 patients (46\%). Coronary atherosclerosis was present in 67 patients (40\%), 26 with obstructive disease. In a univariate analysis several variables were associated with reduced MBF at rest, including male gender, coronary atherosclerosis and elevated LV enddiastolic diameter, and during hyperaemia, including male gender, insulin resistance (IR), smoking habit, LV ejection fraction and end-diastolic diameter. In a multivariate analysis, after adjustment for LV function and for pharmacological
\end{abstract}

R. Liga $\cdot$ C. Vecoli $\cdot$ A. L'Abbate

Scuola Superiore Sant'Anna, Pisa, Italy

D. Rovai · T. Sampietro $\cdot$ C. Caselli • G. Rossi $\cdot$ D. Neglia $(\triangle)$

CNR, Institute of Clinical Physiology, Via G. Moruzzi 1,

56124 Pisa, Italy

e-mail: dneglia@ifc.cnr.it

G. Todiere $\cdot$ D. Neglia

Fondazione Toscana G. Monasterio, Pisa, Italy treatments, male gender was the only independent predictor of reduced MBF at rest $(P<0.001)$, while male gender $(P=0.003)$, IR $(P=0.033)$ and coronary atherosclerosis $(P<0.001)$ remained the only independent predictors of reduced hyperaemic MBF. IR $(P=0.043)$ and coronary atherosclerosis $(P=0.005)$ were the only predictors of depressed MBF reserve. Coronary atherosclerosis, male gender and IR showed additive effects on hyperaemic MBF.

Conclusion In patients with chest pain and normal LV systolic function, IR, male gender and coronary atherosclerosis are independent and additive determinants of impaired hyperaemic MBF.

Keywords Insulin resistance $\cdot$ Endothelial/microvascular dysfunction $\cdot$ PET $\cdot$ MBF

\section{Introduction}

Although chest pain is the most frequent manifestation of coronary artery disease (CAD), even typical chest pain can occur in the absence of significant coronary atherosclerosis [1]. Patients with anginal symptoms and normal coronary arteries, or with minimal irregularities of the coronary wall, often show stress-induced myocardial perfusion abnormalities [2]. In the absence of obstructive coronary atherosclerosis, both symptoms and myocardial perfusion abnormalities are usually attributed to myocardial blood flow (MBF) impairment, secondary to endothelial and/or microvascular dysfunction $[3,4]$.

In several patient categories coronary endothelial/micro vascular dysfunction causing global MBF impairment has been associated with single cardiovascular risk factors [4-6] and with the global risk burden [7]. Moreover, global MBF impairment has also been shown in patients with coronary 
atherosclerosis even in the absence of obstructive CAD [8]. The finding of globally depressed values of absolute MBF on PET is associated with a negative prognosis $[9,10]$.

We undertook this study to investigate the association of cardiovascular risk factors and coronary atherosclerosis with MBF abnormalities in patients with angina-like chest pain with or without obstructive CAD. Because chest pain and MBF impairment are also frequent in patients with normal coronary arteries and depressed left ventricular (LV) function [11], we excluded patients with LV dysfunction.

\section{Materials and methods}

\section{Patient population}

Of the patients referred to our institutions between 2009 and 2011 because of anginal-like chest pain and suspected ischaemic heart disease, 197 consecutive patients with a low-to-intermediate $(<90 \%)$ pretest probability of CAD according to the Diamond and Forrester risk score underwent a combined quantitative evaluation of MBF by PET at rest and after stress, and evaluation of coronary anatomy by invasive coronary angiography or 64-slice CT. As a part of their previous clinical evaluation, 84 patients had also undergone an exercise ECG test, which was positive in 39. Patients with previous myocardial infarction, previous coronary interventions, atrial fibrillation, valvular heart disease of moderate severity or worse, LV systolic dysfunction (ejection fraction $<45 \%$ on two-dimensional echocardiography [12]) and active or known myocardial inflammatory/infective disease were excluded. Patients with insulin-dependent diabetes were also excluded in order to avoid the confounding effects of the use of insulin on some of the variables measured. The presence of coronary atherosclerosis, either non-obstructive ( $<50 \%$ luminal narrowing) or obstructive ( $\geq 50 \%$ luminal narrowing), on invasive or CT angiography was recorded.

Thus, a final population of 167 patients with anginal chest pain and normal coronary arteries (100 patients), nonobstructive coronary atherosclerosis (41 patients) or obstructive coronary atherosclerosis (26 patients) on invasive angiography (110 patients) and/or CT angiography (75 patients) was considered. The quality of the anginal symptoms was classified as atypical or typical according to the current guidelines on the management of stable angina, i.e. substernal chest pain of characteristic quality and duration, provoked by exertion and relieved by rest or nitrates [13]. Of these patients, 15 were enrolled in the EVINCI (Evaluation of Integrated Cardiac Imaging in Ischaemic Heart Disease project, FP7-CP-FP 2007 project, grant agreement no. 222915) multicentre study.

The following cardiovascular risk factors were recorded in every patient: age, gender, family history of premature CAD, non-insulin-dependent diabetes mellitus, hypertension, hypercholesterolaemia (total cholesterol level $\geq 200 \mathrm{mg} / \mathrm{dl}$, low-density lipoprotein cholesterol level $\geq 100 \mathrm{mg} / \mathrm{dl}$ or treatment with lipid-lowering agents), low high-density lipoprotein cholesterol (HDLc, $<40 \mathrm{mg} / \mathrm{dl}$ ), hypertriglyceridaemia $(>150 \mathrm{mg} / \mathrm{dl}$ ), smoking habit, and obesity (body mass index $>30 \mathrm{~kg} / \mathrm{m}^{2}$ ). Accordingly, the Framingham risk score was determined as an indicator of integrated cardiovascular risk. Moreover, in 128 of the 167 patients (77\%), including all the diabetics, the "homeostasis model assessment" (HOMA) index, based on the fasting plasma concentrations of insulin and glucose, was calculated as a measure of global insulin sensitivity [14]. Insulin resistance (IR) was diagnosed in patients with a fasting blood glucose of $>100 \mathrm{mg} / \mathrm{dl}$ and/or a HOMA index of $>2$ [15]. Finally, in each patient LV ejection fraction (biplane Simpson's rule) and LV end-diastolic diameter were recorded on two-dimensional echocardiography.

\section{PET scanning and analysis}

Patients underwent a quantitative myocardial perfusion study using PET, at rest and under dipyridamole stress, no more than 6 weeks from the angiographic evaluation. All patients were clinically stable before, during and after the PET study.

Patients were asked to fast overnight, avoid caffeine and theophylline-containing substances as well as beta-blockers, nondihydropiridine calcium channel blockers and long-acting nitrates in the $48 \mathrm{~h}$ preceding the study and not to take morning blood pressure medications the day of the PET evaluation which was performed on a 24-ring Discovery PET/CT scanner (GE Healthcare, Milwaukee, WI). Sublingual nitrates were allowed for anginal episodes. During imaging, heart rate, blood pressure and nine-lead ECG were monitored. After a scout acquisition, a CT transmission scan (140 $\mathrm{KVp}, 20$ to $30 \mathrm{~mA}$, pitch 1.35) was performed. Next, $7.4 \mathrm{MBq} / \mathrm{kg}$ body weight of ${ }^{13} \mathrm{~N}$-ammonia was infused over a 20 - to 30 -s period. A dynamic acquisition in 2-D mode was started simultaneously with tracer injection $(20$ frames $\times 6 \mathrm{~s}, 6$ frames $\times 30 \mathrm{~s}$ and 3 frames $\times 300 \mathrm{~s}$ ) and was followed by a static acquisition in 3 -D mode $(1$ frame $\times 300 \mathrm{~s})$. After completion of the baseline study and after an additional $30 \mathrm{~min}$ to allow tracer decay, patients underwent pharmacological stress testing with dipyridamole $(0.56 \mathrm{mg} / \mathrm{kg}$ administered intravenously over $4 \mathrm{~min}$ ). Two minutes after completion of the dipyridamole infusion, another dose of ${ }^{13} \mathrm{~N}$-ammonia was administered and PET data were acquired again. Aminophylline (120 to $240 \mathrm{mg}$ ) was infused intravenously $5 \mathrm{~min}$ after tracer injection.

MBF was measured at rest and after dipyridamole infusion by an experienced operator using a previously validated method $[9,11]$. Briefly, the LV myocardium was divided using the standard 17-segment model and ${ }^{13} \mathrm{~N}$-ammonia data were used to compute absolute regional MBF with dedicated software (Munich Heart/NM software) [16], which delineates the 
regions of interest and computes regional $\mathrm{MBF}$ in millilitres per minute per gram. Mean LV MBF was obtained by averaging regional $\mathrm{MBF}$ values of the 17 segments. Resting and hyperaemic MBF were successfully measured in every patient; no side effects occurred with dipyridamole infusion in any patient. LV MBF reserve was computed as the ratio of hyperaemic to resting $\mathrm{MBF}$ and considered abnormal if $<2$ [4]. Moreover, to account for the variability in resting ratepressure product (RPP), the corrected MBF rest [(MBF/ $\mathrm{RPP}) \times 10^{4}$ ] and the corrected MBF reserve (hyperaemic $\mathrm{MBF} /$ corrected MBF rest) were also computed. Finally, coronary vascular resistance (CVR) was calculated as the ratio between mean blood pressure and mean LV MBF at rest and under dipyridamole stress, and expressed in millimetres mercury / millilitres per minute per gram. The summed rest score (SRS), summed stress score (SSS) and summed difference score (SDS), as measures of regional myocardial perfusion heterogeneity, were calculated for the LV using dedicated software (Emory Cardiac Toolbox ${ }^{\mathrm{TM}}$ for PET/CT; GE Healthcare, Milwaukee, WI). The study was approved by the local ethics committee and was in accordance with the Declaration of Helsinki on human research. Written informed consent was obtained from every patient after providing a complete explanation of the protocol, its aims and its potential risks.

\section{Statistical analysis}

Continuous variables are expressed as means \pm SD and categorical variables as percentages. Groups were compared for categorical data using Fisher's exact test and for continuous variables using analysis of variance followed by Fisher's PLSD for multiple comparisons. All tests were two-sided.

Logistic regression, correcting for possible confounders (i.e. pharmacological treatments), was used to identify the determinants among major cardiovascular risk factors and coronary atherosclerosis of impaired myocardial perfusion parameters (MBF, CVR, and MBF reserve) in univariate and multivariate analyses. Only variables with a $P$ value $<0.05$ in univariate analyses were included in the multivariate models. MBFs and CVRs, both at rest and during stress, were considered abnormal for the logistic analyses according to the median values of the pertinent distributions $\left(0.60 \mathrm{ml} \mathrm{min}^{-1} \mathrm{~g}^{-1}\right.$ for

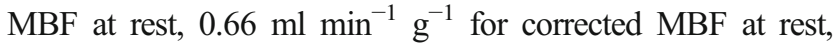
$1.22 \mathrm{ml} \mathrm{min}{ }^{-1} \mathrm{~g}^{-1}$ for MBF during stress, $160.69 \mathrm{mmHg} /$ $\mathrm{ml} \mathrm{min}{ }^{-1} \mathrm{~g}^{-1}$ for CVR at rest, $71.79 \mathrm{mmHg} / \mathrm{ml} \mathrm{min}^{-1} \mathrm{~g}^{-1}$ for CVR during stress). The predictive values of variables are expressed as odds ratios (OR) with corresponding $95 \%$ confidence intervals $(\mathrm{CI})$; the Wald test was used to determine significance. For all tests, a $P$ values $<0.05$ were considered significant.

All analyses were performed using JMP statistical software (SAS Institute Inc.), version 4.0.0, and Stata software (Stata Statistical Software, release 10; StataCorp, College Station, TX).

\section{Results}

Characterization of the population

MBF reserve was preserved $(\geq 2)$ in 90 patients $(54 \%)$, and reduced $(<2)$ in 77 patients $(46 \%)$. Coronary atherosclerosis was detected in 67 patients (40\%), 26 of whom showing obstructive lesions ( $\geq 50 \%$ luminal narrowing) in one (10 patients), two (9 patients) or three coronary vessels (7 patients). The demographic characteristics, clinical presentation, cardiovascular risk factors, LV function and pharmacological treatments of the whole population and of the patients with and without coronary atherosclerosis are presented in Table 1. Patients with coronary atherosclerosis were older $(P=0.009)$ and more frequently symptomatic for typical angina $(P<0.001)$ than those with normal coronary arteries. Conversely, neither the prevalence of major cardiovascular risk factors nor LV functional parameters differed between the two groups. Similarly, no significant differences in demographics, LV functional variables or cardiovascular risk factor prevalence were observed between patients with non-obstructive coronary atherosclerosis and obstructive lesions.

Furthermore, as shown in Table 2, the presence of coronary atherosclerosis was associated with a greater depression of global MBF during hyperaemia $(P<0.001)$ and a greater impairment of $\mathrm{MBF}$ reserve $(P=0.001)$. The difference in $\mathrm{MBF}$ reserve between patients with and without coronary atherosclerosis was maintained even after correcting myocardial perfusion parameters for resting RPP, as an index of myocardial workload. Similarly, patients with coronary atherosclerosis showed significantly greater alterations in measures of regional myocardial perfusion heterogeneity, i.e. SRS, SSS and SDS, than those with normal coronary arteries. Interestingly, while no difference in global MBF parameters were observed between patients with non-obstructive and those with obstructive coronary lesions, the presence of obstructive coronary atherosclerosis was associated with greater impairment in SRS $(P=0.021)$, SSS $(P<0.001)$ and SDS $(P<0.001)$ than nonobstructive disease.

Predictors of reduced myocardial perfusion

As shown in Table 3, several variables were associated with reduced $\mathrm{MBF}$ at rest in the univariate analysis, including male gender, coronary atherosclerosis and elevated LV enddiastolic diameter. Several variables were also associated with reduced MBF during hyperaemia, including coronary atherosclerosis, male gender, IR, smoking habit, LV ejection fraction and end-diastolic diameter.

In the multivariate analysis, after adjustment for LV function and for pharmacological treatments, male gender 
Table 1 Characteristics of patients

\begin{tabular}{|c|c|c|c|c|}
\hline Parameter & Overall $(n=167)$ & $\begin{array}{l}\text { Normal coronary } \\
\text { arteries }(n=100)\end{array}$ & $\begin{array}{l}\text { Coronary } \\
\text { atherosclerosis }(n=67)\end{array}$ & $P$ value \\
\hline \multicolumn{5}{|l|}{ Demographics and symptoms } \\
\hline Age (years), mean $\pm \mathrm{SD}$ & $62 \pm 10$ & $60 \pm 10$ & $64 \pm 10$ & 0.009 \\
\hline Male gender, $n(\%)$ & $96(57)$ & $57(57)$ & $39(58)$ & 0.999 \\
\hline Typical chest pain, $n(\%)$ & $100(60)$ & $46(46)$ & $54(81)$ & $<0.001$ \\
\hline \multicolumn{5}{|l|}{ Cardiovascular risk factors } \\
\hline Family history of CAD, $n(\%)$ & $49(29)$ & $27(27)$ & $22(33)$ & 0.489 \\
\hline Insulin resistance, $n(\%)$ & $85(51)$ & $49(49)$ & $36(54)$ & 0.636 \\
\hline Non-insulin-dependent diabetes, $n(\%)$ & $18(11)$ & $8(8)$ & $10(15)$ & 0.204 \\
\hline Fasting blood glucose (mg/dl), mean (range) & $102(71-205)$ & $102(74-205)$ & $102(71-193)$ & 0.996 \\
\hline Hypercholesterolaemia, $n(\%)$ & $87(52)$ & $49(49)$ & $38(57)$ & 0.347 \\
\hline Low HDLc, $n(\%)$ & $65(39)$ & $37(37)$ & $28(42)$ & 0.627 \\
\hline Hypertriglyceridaemia, $n(\%)$ & $36(22)$ & $25(25)$ & $11(16)$ & 0.249 \\
\hline Hypertension, $n(\%)$ & $94(56)$ & $58(58)$ & $36(54)$ & 0.635 \\
\hline Smoking, $n(\%)$ & $48(29)$ & $32(32)$ & $16(24)$ & 0.297 \\
\hline Obesity, $n(\%)$ & $32(19)$ & $19(19)$ & $13(19)$ & 0.999 \\
\hline Framingham risk score $(\%)$, mean $\pm \mathrm{SD}$ & $14 \pm 11$ & $14 \pm 11$ & $15 \pm 12$ & 0.383 \\
\hline \multicolumn{5}{|l|}{ LV structure and function, mean $\pm \mathrm{SD}$} \\
\hline LV ejection fraction $(\%)$ & $56 \pm 9$ & $56 \pm 9$ & $57 \pm 10$ & 0.826 \\
\hline LV end-diastolic diameter (mm) & $51 \pm 6$ & $52 \pm 6$ & $50 \pm 6$ & 0.052 \\
\hline \multicolumn{5}{|l|}{ Pharmacological treatments, $n(\%)$} \\
\hline ACE inhibitors or angiotensin receptor blockers & $88(53)$ & $56(56)$ & $32(47)$ & 0.344 \\
\hline Beta-blockers & $36(22)$ & $33(33)$ & $27(40)$ & 0.411 \\
\hline Calcium channel blockers & $34(20)$ & $23(23)$ & $11(16)$ & 0.333 \\
\hline Nitrates & $18(11)$ & $5(5)$ & $13(19)$ & 0.005 \\
\hline Diuretics & $43(26)$ & $30(30)$ & $13(19)$ & 0.150 \\
\hline Statins or fibrates & $44(26)$ & $15(15)$ & $29(43)$ & $<0.001$ \\
\hline Oral antidiabetics & $16(10)$ & $6(6)$ & $10(15)$ & 0.064 \\
\hline
\end{tabular}

$(P<0.001)$ was the only independent predictor of reduced $\quad 95 \%$ CI $1.05-3.96, P=0.036)$. Coronary atherosclerosis MBF at rest and of reduced corrected MBF at rest (OR 2.04, $\quad(P<0.001)$, IR $(P=0.033)$, LV ejection fraction $(P=0.010)$

Table 2 Myocardial perfusion parameters on PET

\begin{tabular}{|c|c|c|c|c|c|c|}
\hline Parameter & $\begin{array}{l}\text { Overall } \\
(n=167)\end{array}$ & $\begin{array}{l}\text { Normal coronary } \\
\text { arteries }(n=100)\end{array}$ & $\begin{array}{l}\text { Coronary } \\
\text { atherosclerosis } \\
(n=67)\end{array}$ & $P$ value & $\begin{array}{l}<50 \% \text { coronary } \\
\text { stenosis }(n=41)\end{array}$ & $\begin{array}{l}\geq 50 \% \text { coronary } \\
\text { stenosis }(n=26)\end{array}$ \\
\hline RPP at rest & $9,048 \pm 2,384$ & $9,298 \pm 2,671$ & $8,705 \pm 1,892$ & 0.134 & $8,685 \pm 1,820$ & $8,734 \pm 2,034$ \\
\hline RPP during hyperaemia & $11,020 \pm 3,020$ & $11,212 \pm 3,342$ & $10,760 \pm 2,494$ & 0.387 & $10,720 \pm 2,716$ & $10,816 \pm 2,197$ \\
\hline $\mathrm{MBF}$ at rest $\left(\mathrm{ml} \mathrm{min}{ }^{-1} \mathrm{~g}^{-1}\right)$ & $0.61 \pm 0.17$ & $0.64 \pm 0.18$ & $0.58 \pm 0.16$ & 0.015 & $0.60 \pm 0.17$ & $0.55 \pm 0.15^{*}$ \\
\hline Corrected MBF at rest $\left(\mathrm{ml} \mathrm{min} \operatorname{mg}^{-1}\right)$ & $0.70 \pm 0.21$ & $0.72 \pm 0.22$ & $0.67 \pm 0.19$ & 0.129 & $0.69 \pm 0.21$ & $0.64 \pm 0.16$ \\
\hline MBF during stress $\left(\mathrm{ml} \mathrm{min}^{-1} \mathrm{~g}^{-1}\right)$ & $1.28 \pm 0.48$ & $1.41 \pm 0.49$ & $1.08 \pm 0.38$ & $<0.001$ & $1.14 \pm 0.41 * *$ & $0.97 \pm 0.31 * *$ \\
\hline MBF reserve & $2.13 \pm 0.73$ & $2.29 \pm 0.77$ & $1.91 \pm 0.59$ & 0.001 & $1.98 \pm 0.64 *$ & $1.79 \pm 0.51 * *$ \\
\hline Corrected MBF reserve & $1.89 \pm 0.74$ & $2.06 \pm 0.81$ & $1.69 \pm 0.60$ & 0.002 & $1.76 \pm 0.66 *$ & $1.56 \pm 0.47 * *$ \\
\hline MBF reserve <2, $n(\%)$ & $77(46)$ & $37(37)$ & $40(60)$ & 0.005 & $22(54)$ & $18(69)^{* *}$ \\
\hline Summed rest score & $3.1 \pm 5.7$ & $1.6 \pm 3.1$ & $5.3 \pm 7.7$ & 0.002 & $3.8 \pm 6.2$ & $7.2 \pm 8.9^{* *}, \dagger^{\dagger}$ \\
\hline Summed stress score & $4.4 \pm 6.6$ & $2.3 \pm 3.8$ & $7.4 \pm 8.4$ & $<0.001$ & $4.6 \pm 6.3$ & $10.9 \pm 9.5 * *, \dagger$ \\
\hline Summed difference score & $1.3 \pm 2.6$ & $0.8 \pm 1.7$ & $2.1 \pm 3.3$ & 0.003 & $0.8 \pm 1.8$ & $3.7 \pm 3.9 * * \dagger \dagger$ \\
\hline
\end{tabular}

${ }^{*} P<0.05,{ }^{*} P<0.01$, vs. normal ${ }^{\dagger} P<0.05,{ }^{\dagger \dagger} P<0.01$, vs. $<50 \%$ coronary stenosis 
Table 3 Determinants of myocardial blood flow

\begin{tabular}{|c|c|c|c|c|c|c|c|c|}
\hline \multirow[t]{2}{*}{ Variables } & \multicolumn{4}{|c|}{ Depressed resting MBF $\left(<0.60 \mathrm{ml} \mathrm{min}{ }^{-1} \mathrm{~g}^{-1}\right)$} & \multicolumn{4}{|c|}{ Depressed dipyridamole MBF $\left(<1.22 \mathrm{ml} \mathrm{min}^{-1} \mathrm{~g}^{-1}\right)$} \\
\hline & $\begin{array}{l}\text { Univariate } \\
\text { OR }(95 \% \mathrm{CI})\end{array}$ & $P$ value & $\begin{array}{l}\text { Multivariate } \\
\text { OR }(95 \% \mathrm{CI})\end{array}$ & $P$ value & $\begin{array}{l}\text { Univariate } \\
\text { OR }(95 \% \mathrm{CI})\end{array}$ & $P$ value & $\begin{array}{l}\text { Multivariate } \\
\text { OR }(95 \% \mathrm{CI})\end{array}$ & $P$ value \\
\hline Age $(n)$ & $1.01(0.98-1.04)$ & 0.443 & NA & NA & $1.01(0.98-1.04)$ & 0.747 & NA & NA \\
\hline Gender (male) & $4.74(2.43-9.25)$ & $<0.001$ & $5.11(2.32-11.29)$ & $<0.001$ & $3.19(1.67-6.06)$ & $<0.001$ & $4.02(1.88-8.61)$ & 0.003 \\
\hline Typical chest pain (1-0) & $1.82(0.96-3.43)$ & 0.065 & NA & NA & $2.14(1.14-4.03)$ & 0.019 & NS & NS \\
\hline $\begin{array}{l}\text { Coronary atherosclerosis } \\
\quad(1-0)\end{array}$ & $1.98(1.05-3.73)$ & 0.035 & NS & NS & $4.01(2.10-7.87)$ & $<0.001$ & $4.87(2.24-10.58)$ & $<0.001$ \\
\hline $\begin{array}{c}<50 \% \text { coronary } \\
\text { stenosis }(1-0)\end{array}$ & $1.61(0.77-3.35)$ & 0.208 & - & - & $2.37(1.13-4.98)$ & 0.022 & - & - \\
\hline $\begin{array}{l}\geq 50 \% \text { coronary } \\
\text { stenosis }(1-0)\end{array}$ & $2.83(1.12-7.12)$ & 0.028 & - & - & $14.24(3.99-50.78)$ & $<0.001$ & - & - \\
\hline $\begin{array}{l}\text { Family history } \\
\text { of CAD (1-0) }\end{array}$ & $0.93(0.48-1.83)$ & 0.841 & NA & NA & $0.64(0.33-1.27)$ & 0.202 & NA & NA \\
\hline Smoking $(1-0)$ & $1.18(0.60-2.32)$ & 0.627 & NA & NA & $2.22(1.12-4.42)$ & 0.023 & NS & NS \\
\hline Insulin resistance $(1-0)$ & $1.40(0.76-2.59)$ & 0.279 & NA & NA & $2.13(1.15-3.95)$ & 0.017 & $2.21(1.07-4.58)$ & $\mathbf{0 . 0 3 3}$ \\
\hline Fasting blood glucose (mg/dl) & $1.01(0.99-1.02)$ & 0.369 & NA & NA & $1.01(0.99-1.02)$ & 0.289 & NA & NA \\
\hline Hypercholesterolaemia (1-0) & $1.15(0.62-2.13)$ & 0.653 & NA & NA & $0.74(0.40-1.35)$ & 0.322 & NA & NA \\
\hline Low HDLc $(1-0)$ & $1.62(0.86-3.05)$ & 0.134 & NA & NA & $2.14(1.14-4.04)$ & 0.018 & NS & NS \\
\hline $\begin{array}{l}\text { Hypertriglyceridaemia } \\
\quad(1-0)\end{array}$ & $1.61(0.74-3.51)$ & 0.229 & NA & NA & $0.94(0.45-1.96)$ & 0.862 & NA & NA \\
\hline Hypertension (1-0) & $1.04(0.56-1.93)$ & 0.902 & NA & NA & $0.58(0.31-1.07)$ & 0.082 & NA & NA \\
\hline Obesity $(1-0)$ & $0.94(0.44-2.04)$ & 0.878 & NA & NA & $0.67(0.31-1.47)$ & 0.323 & NA & NA \\
\hline LV ejection fraction (\%) & $0.98(0.94-1.01)$ & 0.195 & NA & NA & $0.95(0.92-0.99)$ & 0.011 & $0.95(0.91-0.99)$ & 0.010 \\
\hline $\begin{array}{l}\text { LV end-diastolic diameter } \\
\quad(\mathrm{mm})\end{array}$ & $1.06(1.01-1.12)$ & 0.036 & NA & NA & $1.06(1.00-1.12)$ & 0.039 & NA & NA \\
\hline Beta blockers $(1-0)$ & $1.21(0.64-2.29)$ & 0.562 & NA & NA & $1.35(0.72-1.55)$ & 0.350 & NA & NA \\
\hline $\begin{array}{l}\text { Calcium channel } \\
\text { blockers }(1-0)\end{array}$ & $1.41(0.64-3.09)$ & 0.398 & NA & NA & $0.59(0.27-1.28)$ & 0.182 & NA & NA \\
\hline $\begin{array}{l}\text { ACE inhibitors or angiotensin } \\
\text { receptor blockers }(1-0)\end{array}$ & $0.99(0.54-1.84)$ & 0.988 & NA & NA & $1.38(0.75-2.53)$ & 0.304 & NA & NA \\
\hline Diuretics $(1-0)$ & $0.77(0.39-1.56)$ & 0.473 & NA & NA & $1.31(0.65-2.62)$ & 0.448 & NA & NA \\
\hline Nitrates $(1-0)$ & $1.58(0.49-5.05)$ & 0.441 & NA & NA & $3.89(1.03-14.71)$ & 0.031 & NS & NS \\
\hline
\end{tabular}

Significant associations with reduced MBF are indicated in bold type

$1-0$ indicates the presence of a categorical variable ( $1=$ present, $0=$ absent $)$

$N A$ not applicable, $N S$ not significant

and again male gender $(P=0.003)$ remained the only independent predictors of reduced MBF during hyperaemia. Similarly, after adjustment for the same variables, male gender remained a significant predictor of higher resting CVR (OR 5.26, $95 \%$ CI $2.59-10.71, P<0.001$ ), while IR (OR 2.02, $95 \%$ CI $1.01-4.05, P=0.046$ ), male gender (OR 2.38, $95 \% \mathrm{CI}$ $1.17-4.83, P=0.016)$ and coronary atherosclerosis (OR $2.61,95 \%$ CI $1.26-5.42, P=0.010)$ were the only independent determinants of increased CVR during hyperaemia. Finally, IR (OR 1.92, $95 \%$ CI 1.02-3.62, $P=0.043$ ) and coronary atherosclerosis (OR 2.51, $95 \%$ CI 1.32-4.77, $P=0.005$ ) were the only independent predictors of depressed MBF reserve. The same two variables, IR $(P=0.026)$ and coronary atherosclerosis $(P=0.043)$, also remained independent predictors of corrected MBF reserve. The synergistic effects of IR, coronary atherosclerosis and male gender in impairing MBF during hyperaemia are illustrated in Fig. 1.

Male gender, coronary atherosclerosis and myocardial perfusion

As shown in Table 4, in our population male patients were significantly younger than female patients $(P=0.008)$ despite showing a similar prevalence and severity of coronary atherosclerotic disease. Interestingly, while the prevalence of typical angina did not differ between genders, female patients complained of dipyridamole-induced chest pain less frequently than male patients $(P=0.039)$. Furthermore, male patients 


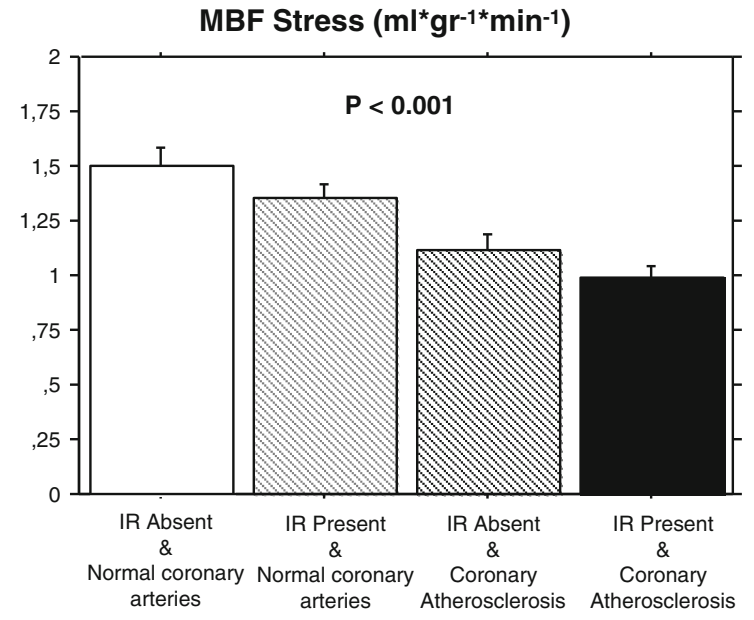

Fig. 1 Effects of insulin resistance (IR), coronary atherosclerosis and male gender on MBF during hyperaemia. a Additive effect of IR and coronary atherosclerosis in depressing hyperaemic MBF. b Similar

showed a more altered global myocardial perfusion, both at rest $(P<0.001)$ and during hyperaemia $(P<0.001)$, than female patients. Interestingly, the effect of male gender on MBF regulation was confirmed even after correction for different variables, including patient age (Table 3). No differences in semiquantitative measures of regional myocardial perfusion heterogeneity, i.e. SRS, SSS and SDS, were observed between the two groups.

The combined effects of gender and coronary anatomy and of gender and symptoms on hyperaemic MBF are illustrated in Fig. 2. Male gender and coronary anatomy had individual and synergistic effects on hyperaemic MBF. An association between depressed MBF with typical angina was evident only in male patients.

\section{Discussion}

IR was a major predictor of depressed global hyperaemic MBF and flow reserve in patients with anginal chest pain and normal LV systolic function. This relationship was independent and additive for male gender and coronary atherosclerosis, suggesting a relevant role for metabolically related coronary endothelial/microvascular dysfunction in these patients.

Metabolic determinants of myocardial perfusion abnormalities

Global cardiovascular risk burden is associated with depressed MBF reserve in patients with chest pain independently of the presence of significant CAD [7, 8]. Recently, Danad et al. have

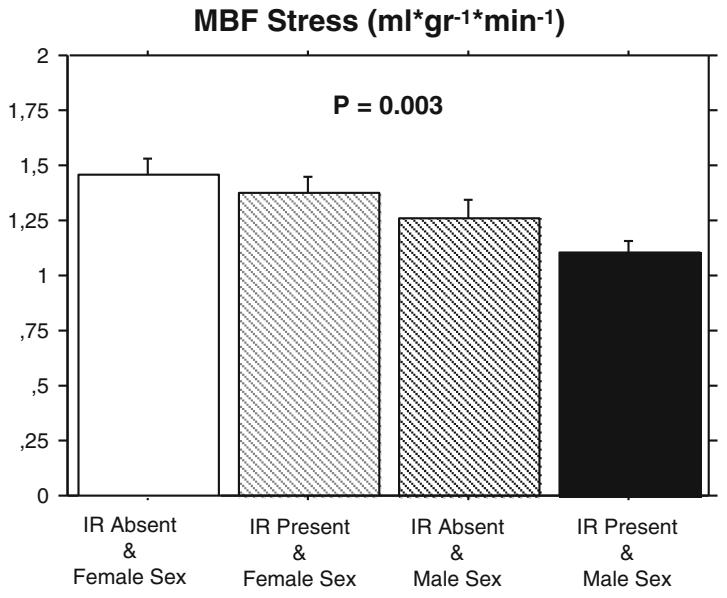

synergistic effect of altered glucose homeostasis and male gender in impairing hyperaemic MBF

reported that specific variables, such as age, gender, diabetes and BMI, independently predict impaired hyperaemic MBF in patients with a low/intermediate probability of CAD and normal coronary arteries [17]. Our study extends previous observations in a wider population of patients with anginal chest pain, normal LV systolic function with or without coronary atherosclerosis. In the present study, a specific metabolic cardiovascular risk factor - namely IR - was found to be a major independent determinant of depressed myocardial perfusion. IR frequently clusters with other metabolic risk factors, such as obesity and low HDLc, and may represent an earlier stage of a metabolic syndrome known to significantly alter MBF regulation [18]. Also in our study IR and obesity were correlated, although only IR had significant effects on myocardial perfusion parameters. Of note, the association between IR and depressed myocardial perfusion persisted even after correction for blood pressure and RPP, as indicators of myocardial workload.

In patients with IR a decreased coronary vasodilatory function and a depressed MBF reserve on cardiac PET have been documented $[19,20]$. On the other hand, a reciprocal relationship between endothelial dysfunction and IR has been suggested in both experimental and clinical studies [21, 22]. Interestingly, while in previous studies the association between IR and altered myocardial vasodilatory response to dipyridamole stress seemed to be mainly driven by the presence of hyperglycaemia [19], more recent studies have documented the existence of a linear relationship between the HOMA index and MBF reserve in patients with or without overt diabetes [20]. While the design of the present study prevented the evaluation of the mechanistic effects of IR on MBF regulation, our results show that the detrimental effect of IR on MBF regulation is multifactorial, involving both 
Table 4 Patient characteristics in relation to gender

\begin{tabular}{|c|c|c|c|}
\hline Parameter & $\begin{array}{l}\text { Male gender } \\
(n=96)\end{array}$ & $\begin{array}{l}\text { Female gender } \\
(n=71)\end{array}$ & $\begin{array}{l}P \\
\text { value }\end{array}$ \\
\hline \multicolumn{4}{|l|}{ Demographics and symptoms } \\
\hline Age (years), mean $\pm \mathrm{SD}$ & $60 \pm 10$ & $64 \pm 10$ & 0.008 \\
\hline Typical chest pain, $n(\%)$ & $56(58)$ & $44(62)$ & 0.750 \\
\hline $\begin{array}{l}\text { Positive exercise } \\
\text { ECG, } n(\%)\end{array}$ & $21(22)$ & $18(25)$ & 0.829 \\
\hline $\begin{array}{l}\text { Dipyridamole-induced } \\
\text { angina, } n(\%)\end{array}$ & $15(16)$ & $21(30)$ & 0.037 \\
\hline \multicolumn{4}{|l|}{ LV structure and function } \\
\hline $\begin{array}{l}\text { Ejection fraction }(\%) \text {, } \\
\text { mean } \pm \mathrm{SD}\end{array}$ & $56 \pm 9$ & $57 \pm 9$ & 0.344 \\
\hline $\begin{array}{l}\text { End-diastolic diameter } \\
(\mathrm{mm}), \text { mean } \pm \mathrm{SD}\end{array}$ & $53 \pm 5$ & $49 \pm 6$ & $<0.001$ \\
\hline \multicolumn{4}{|l|}{ Coronary anatomy, $n(\%)$} \\
\hline Normal coronary arteries & $57(59)$ & $43(61)$ & 0.999 \\
\hline $\begin{array}{l}\text { Non-obstructive } \\
\text { atherosclerosis }(<50 \%)\end{array}$ & $23(24)$ & $18(25)$ & 0.857 \\
\hline $\begin{array}{l}\text { Obstructive } \\
\text { atherosclerosis }(\geq 50 \%)\end{array}$ & $16(17)$ & $10(14)$ & 0.674 \\
\hline \multicolumn{4}{|l|}{$\mathrm{PET}$ data, mean $\pm \mathrm{SD}$} \\
\hline $\begin{array}{l}\text { MBF at rest } \\
\left(\mathrm{ml} \mathrm{min} \min ^{-1} \mathrm{~g}^{-1}\right)\end{array}$ & $0.56 \pm 0.16$ & $0.68 \pm 0.17$ & $<0.001$ \\
\hline $\begin{array}{l}\text { Corrected MBF at rest } \\
\left(\mathrm{ml} \mathrm{min}-1 \mathrm{~g}^{-1}\right)\end{array}$ & $0.69 \pm 0.21$ & $0.74 \pm 0.20$ & 0.034 \\
\hline 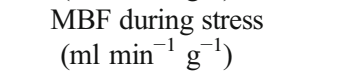 & $1.17 \pm 0.47$ & $1.42 \pm 0.45$ & $<0.001$ \\
\hline MBF reserve & $2.06 \pm 0.64$ & $2.22 \pm 0.83$ & 0.168 \\
\hline Corrected MBF reserve & $1.80 \pm 0.60$ & $2.03 \pm 0.88$ & 0.065 \\
\hline Summed rest score & $3.82 \pm 6.67$ & $2.19 \pm 3.95$ & 0.112 \\
\hline Summed stress score & $5.18 \pm 7.75$ & $3.46 \pm 4.65$ & 0.146 \\
\hline Summed difference score & $1.40 \pm 2.67$ & $1.23 \pm 2.39$ & 0.717 \\
\hline
\end{tabular}

$L V$ left ventricle, $M B F$ myocardial blood flow, $C V R$ coronary vascular resistance functional abnormalities of the coronary circulation as well as the known causal relationships with coronary atherosclerosis. IR has already been associated with impaired coronary endothelial [19] and microvascular function [20]. The present and previous studies underline the association between IR and altered coronary vasodilatory function in patients with anginal chest pain, with or without coronary atherosclerosis, even in the absence of frank diabetes mellitus.

Our group has recently reported an association of IR and low HDLc with more severe contractile and perfusion abnormalities in patients with idiopathic LV dysfunction [23]. Low HDLc levels have been reported in patients with dilated cardiomyopathy and have been associated with deleterious effects on endothelial function [24]. The present study extends the association between specific metabolic risk factors and MBF abnormalities in a different population of patients with anginal chest pain, demonstrating that the detrimental interaction between metabolic derangement and MBF is independent of LV systolic function and coronary atherosclerosis. In our study, while IR and low HDLc clustered together, only the former was an independent determinant of impaired coronary vasodilatory function. Interestingly, low HDLc was confirmed as a predictor, although in the univariate analysis, of globally depressed hyperaemic myocardial perfusion.

Investigation of the causal relationships between these determinants and their mechanisms of action on the coronary vessels were beyond the scope of our study. Nevertheless, our results further underline the concept that PET-mediated absolute MBF quantitation allows an integrated evaluation of coronary vascular function, enabling a description of the abnormal response of the coronary circulation to multiple determinants.

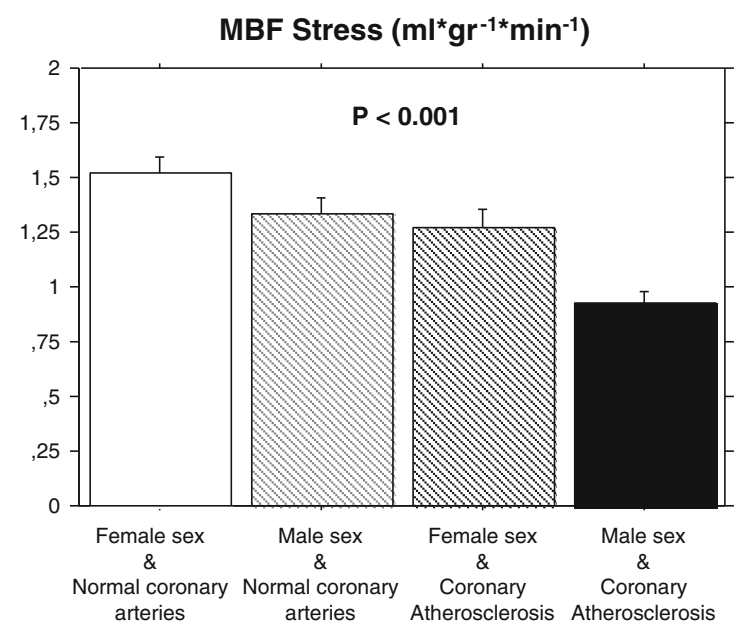

Fig. 2 Effects of gender and coronary anatomy on MBF during hyperaemia. a Additive and independent effects of coronary atherosclerosis and male gender in depressing hyperaemic MBF. b Effects of gender and

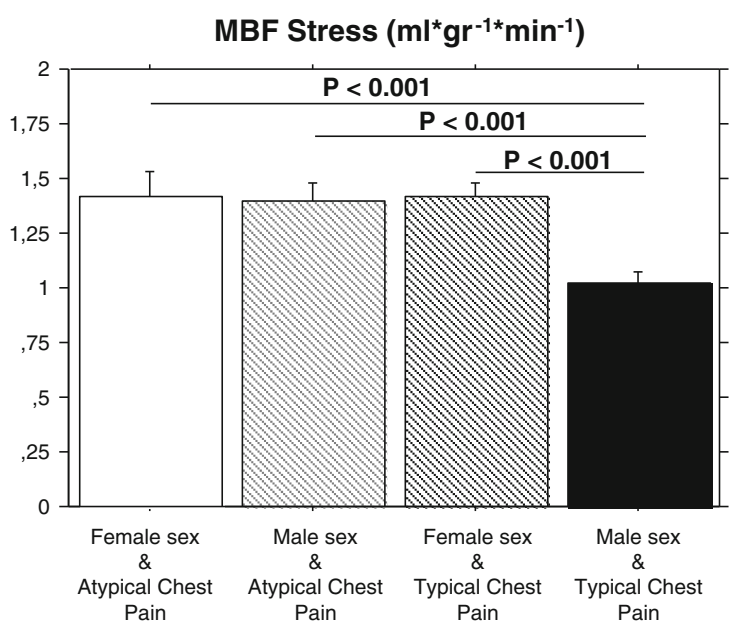

anginal symptoms. An association between typical angina and depressed MBF is evident only in male patients 
Effects of diffuse atherosclerosis and male gender on myocardial perfusion

In the absence of significant $\mathrm{CAD}$, depressed $\mathrm{MBF}$ reserve is generally attributed to coronary microvascular dysfunction [4]. However, even in patients with coronary atherosclerosis there is an unexpected variability in $\mathrm{MBF}$ and flow reserve [25], possibly as a result of endothelial/microvascular dysfunction secondary to the effects of cardiovascular risk factors [4-8]. Moreover, the role of diffuse, nonsignificant, coronary atherosclerosis, as assessed by CT coronary angiography, in impairing downstream myocardial perfusion has also been demonstrated [8]. In the present study, a sizeable proportion of the population showed non-obstructive atherosclerosis on coronary angiography, which can be considered as a surrogate index of diffuse atherosclerosis. This condition was associated with a similar reduction of global hyperaemic MBF as observed in patients with obstructive coronary lesions. Our results thus underline the relevance of a combined evaluation of coronary anatomy and function in order to obtain a comprehensive assessment of MBF regulation in anginal patients at risk of CAD. In our study, coronary atherosclerosis synergistically interacted with IR in impairing hyperaemic MBF. However, our data clearly show how the relationship between IR and MBF is unaffected by epicardial coronary anatomy and is responsible for a significant impairment in global myocardial perfusion.

Finally, our data confirmed the existence of a significant association between male gender and impaired global MBF. The correlation between gender and depressed hyperaemic MBF has recently been reported in patients with normal coronary arteries [17]. Our data extend these observations by showing that male gender is associated with a marked alteration of global myocardial perfusion, both at rest and during stress. This association persists even after correction for patient RPP, as well as for increasing age, a variable already associated with depressed MBF regulation [26]. Our results are in line with those of previous studies in which genderrelated differences in $\mathrm{MBF}$ regulation were attributed to the more favourable lipid profile seen in women [27]. The present results further underline the existence of an independent detrimental association between male gender and MBF regulation in patients with anginal chest pain, and underline the importance of including gender differences when normal values of resting and hyperaemic MBF are defined.

In our study, typical angina was more frequent in patients with obstructive CAD, but was loosely associated with reduced hyperaemic MBF in the overall population. Nevertheless, typical chest pain when occurring in male patients was associated with a more depressed hyperaemic MBF. However, investigation of the causal relationships among gender, depressed MBF and typical angina was beyond the scope of the present study.
Limitations

Because of consecutive enrolment the population of patients was not homogeneous, i.e. with or without LV systolic dysfunction. Moreover, the inclusion of a parallel group of healthy controls without cardiovascular risk factors might have helped to better identify some weaker predictors of MBF abnormalities. Accordingly, our analyses were able to characterize only the "strongest" determinants of myocardial perfusion abnormalities in a representative population of anginal patients with a low/intermediate probability of CAD. Secondly, since either invasive or CT coronary angiography were performed to exclude the presence of coronary stenoses, the atherosclerotic burden could only be measured quantitatively in the subpopulation submitted to $\mathrm{CT}$, and was not considered in the analysis.

Another limitation concerns the exclusion of patients with insulin-dependent diabetes. We decided to exclude these subjects in order to avoid the effect of insulin treatment on the metabolic variables measured, such as HOMA index, and to better elucidate the possible independent effects of single cardiovascular risk factors on MBF. While in the majority of patients the presence of IR was diagnosed according to the HOMA index, in a sizeable proportion of our population IR was defined based on fasting blood glucose levels. Abnormal fasting blood glucose levels were not associated with MBF abnormalities in the multivariate analysis, and thus an independent detrimental effect of IR per se on hyperaemic myocardial perfusion can be suspected. We carefully evaluated the clinical history and glycaemic levels under fasting conditions as inclusion criteria, but neither an oral glucose tolerance test nor a hyperinsulinaemic euglycaemic clamp assay was performed. Although the latter is considered the reference method, the HOMA index has been consistently shown to mirror its results and has been proposed for the evaluation of glycometabolic metabolism when only fasting blood samples are available [14]. Moreover, in contrast to previous studies [17], our study did not demonstrate an independent effect of increasing age in depressing myocardial perfusion. However, the composition of our patient population, i.e. the inclusion of patients with $\mathrm{CAD}$, might explain this differences. In fact, since in our study the presence of coronary atherosclerosis, the strongest predictor of impaired hyperaemic MBF, correlated with older age, the possible association of this constitutional variable with $\mathrm{MBF}$ abnormalities might have been obscured.

Furthermore, due to the high prevalence of hypertensive subjects in our population, some vasoactive substances were not discontinued prior to PET evaluation. While this could have somewhat affected MBF measurement, no specific pharmacological treatment was an independent predictor of depressed MBF in the multivariate analyses. Finally, to avoid the possible effects on MBF regulation of vasoactive substances, i.e. nitrates and intravenous beta blockers, frequently administrated before CT angiography, PET and CT imaging were performed in different sessions. 


\section{Conclusion}

This study showed that IR is a major independent determinant of impaired global MBF reserve in patients with anginal chest pain and normal LV systolic function. These effects were independent of the presence of atherosclerotic CAD and of gender. The present results suggest the relevant role of metabolically related coronary endothelial/microvascular dysfunction in this category of patients.

Acknowledgments We thank Piero Salvadori, Luca Menichetti and Silvia Pardini for their participation to the cardiac PET studies. This study was partially supported by a grant from the European Union FP7-CP-FP 2007 project (grant agreement no. 222915, EVINCI).

Conflicts of interest None.

\section{References}

1. Cannon RO 3rd. Microvascular angina and the continuing dilemma of chest pain with normal coronary angiograms. J Am Coll Cardiol. 2009;54:877-85.

2. Lanza GA, Buffon A, Sestito A, Natale L, Sgueglia GA, Galiuto L, et al. Relation between stress-induced myocardial perfusion defects on cardiovascular magnetic resonance and coronary microvascular dysfunction in patients with cardiac syndrome X. J Am Coll Cardiol. 2008;51:466-72.

3. Bøttcher M, Bøtker HE, Sonne H, Nielsen TT, Czernin J. Endothelium-dependent and -independent perfusion reserve and the effect of L-arginine on myocardial perfusion in patients with syndrome X. Circulation. 1999;99:1795-801.

4. Camici PG, Crea F. Coronary microvascular dysfunction. N Engl J Med. 2007;356:830-40.

5. Di Carli MF, Janisse J, Grunberger G, Ager J. Role of chronic hyperglycemia in the pathogenesis of coronary microvascular dysfunction in diabetes. J Am Coll Cardiol. 2003;41:1387-93.

6. Kaufmann PA, Gnecchi-Ruscone T, di Terlizzi M, Schäfers KP, Lüscher TF, Camici PG. Coronary heart disease in smokers: vitamin $\mathrm{C}$ restores coronary microcirculatory function. Circulation. 2000; 102:1233-8.

7. Dorbala S, Hassan A, Heinonen T, Schelbert HR, Di Carli MF, RAMPART Investigators. Coronary vasodilator reserve and Framingham risk scores in subjects at risk for coronary artery disease. J Nucl Cardiol. 2006;13:761-7.

8. Liga R, Marini C, Coceani M, Filidei E, Schlueter M, Bianchi M, et al. Structural abnormalities of the coronary arterial wall - in addition to luminal narrowing - affect myocardial blood flow reserve. J Nucl Med. 2011;52:1704-12.

9. Neglia D, Michelassi C, Trivieri MG, Sambuceti G, Giorgetti A, Pratali $\mathrm{L}$, et al. Prognostic role of myocardial blood flow impairment in idiopathic left ventricular dysfunction. Circulation. 2002;105:186-93.

10. Tio RA, Dabeshlim A, Siebelink HM, de Sutter J, Hillege HL, Zeebregts CJ, et al. Comparison between the prognostic value of left ventricular function and myocardial perfusion reserve in patients with ischemic heart disease. J Nucl Med. 2009;50:214-9.

11. Neglia D, Parodi O, Gallopin M, Sambuceti G, Giorgetti A, Pratali L, et al. Myocardial blood flow response to pacing tachycardia and to dipyridamole infusion in patients with dilated cardiomyopathy without overt heart failure. A quantitative assessment by positron emission tomography. Circulation. 1995;92:796-804.
12. Shah SJ, Heitner JF, Sweitzer NK, Anand IS, Kim HY, Harty B, et al. Baseline characteristics of patients in the treatment of preserved cardiac function heart failure with an aldosterone antagonist trial. Circ Heart Fail. 2013;6:184-92.

13. Fox K, Garcia MA, Ardissino D, Buszman P, Camici PG, Crea F, et al. Guidelines on the management of stable angina pectoris: executive summary: The Task Force on the Management of Stable Angina Pectoris of the European Society of Cardiology. Eur Heart J. 2006;27:1341-81.

14. Bonora E, Targher G, Alberiche M, Bonadonna RC, Saggiani F, Zenere MB, et al. Homeostasis model assessment closely mirrors the glucose clamp technique in the assessment of insulin sensitivity: studies in subjects with various degrees of glucose tolerance and insulin sensitivity. Diabetes Care. 2000;23:57-63.

15. Rydén L, Standl E, Bartnik M, Van den Berghe G, Betteridge J, de Boer MJ, et al. Guidelines on diabetes, pre-diabetes, and cardiovascular diseases: executive summary. The Task Force on Diabetes and Cardiovascular Diseases of the European Society of Cardiology (ESC) and of the European Association for the Study of Diabetes (EASD). Eur Heart J. 2007;28:88-136.

16. Nekolla SG, Miethaner C, Nguyen N, Ziegler SI, Schwaiger M. Reproducibility of polar map generation and assessment of defect severity and extent assessment in myocardial perfusion imaging using positron emission tomography. Eur J Nucl Med. 1998;25:1313-21.

17. Danad I, Raijmakers PG, Appelman YE, Harms HJ, de Haan S, van den Oever ML, et al. Coronary risk factors and myocardial blood flow in patients evaluated for coronary artery disease: a quantitative [15O]H2O PET/CT study. Eur J Nucl Med Mol Imaging. 2012;39:102-12.

18. Di Carli MF, Charytan D, McMahon GT, Ganz P, Dorbala S, Schelbert HR. Coronary circulatory function in patients with the metabolic syndrome. J Nucl Med. 2011;52:1369-77.

19. Prior JO, Quiñones MJ, Hernandez-Pampaloni M, Facta AD, Schindler TH, Sayre JW, et al. Coronary circulatory dysfunction in insulin resistance, impaired glucose tolerance, and type 2 diabetes mellitus. Circulation. 2005;111:2291-8.

20. Picchi A, Limbruno U, Focardi M, Cortese B, Micheli A, Boschi L, et al. Increased basal coronary blood flow as a cause of reduced coronary flow reserve in diabetic patients. Am J Physiol Heart Circ Physiol. 2011;301:H2279-84.

21. Vecoli C, Andreassi MG, Liga R, Colombo MG, Coceani M, Carpeggiani $\mathrm{C}$, et al. $\mathrm{T}(-786) \rightarrow \mathrm{C}$ polymorphism of the endothelial nitric oxide synthase gene is associated with insulin resistance in patients with ischemic or non ischemic cardiomyopathy. BMC Med Genet. 2012;13:92.

22. Kim JA, Montagnani M, Koh KK, Quon MJ. Reciprocal relationships between insulin resistance and endothelial dysfunction: molecular and pathophysiological mechanisms. Circulation. 2006;113:1888-904.

23. Neglia D, Sampietro T, Vecoli C, Liga R, Rossi G, Filidei E, et al. Abnormal glucose and lipid control in non-ischemic left ventricular dysfunction. J Nucl Cardiol. 2012;19:1182-9.

24. Sampietro T, Neglia D, Bionda A, Dal Pino B, Bigazzi F, Puntoni M, et al. Inflammatory markers and serum lipids in idiopathic dilated cardiomyopathy. Am J Cardiol. 2005;96:1718-20.

25. Meijboom WB, Van Mieghem CA, van Pelt N, Weustink A, Pugliese F, Mollet NR, et al. Comprehensive assessment of coronary artery stenoses: computed tomography coronary angiography versus conventional coronary angiography and correlation with fractional flow reserve in patients with stable angina. J Am Coll Cardiol. 2008;52:636-43.

26. Chareonthaitawee P, Kaufmann PA, Rimoldi O, Camici PG. Heterogeneity of resting and hyperemic myocardial blood flow in healthy humans. Cardiovasc Res. 2001;50:151-61.

27. Duvernoy CS, Meyer C, Seifert-Klauss V, Dayanikli F, Matsunari I, Rattenhuber J, et al. Gender differences in myocardial blood flow dynamics: lipid profile and hemodynamic effects. J Am Coll Cardiol. 1999;33:463-70. 